\title{
Yabancı Ot İlaçlarına Dayanıklı Bazı Çeltik (Oryza sativa L.) Genotiplerinin Geliştirilmesi
}

\author{
*Halil SÜREK ${ }^{1}$ Rasim ÜNAN¹ Necmi BEŞER ${ }^{2}$ Recep KAYA ${ }^{1}$ Adnan KARA ${ }^{3}$ \\ ${ }^{1}$ Trakya Tarımsal Araştırma Enstitüsü, Edirne \\ ${ }^{2}$ Trakya Üniversitesi, Mühendislik Fakültesi, Genetik ve Biyomühendislik Bölümü, Edirne \\ ${ }^{3}$ Namık Kemal Üniversitesi, Ziraat Fakültesi, Bitki Koruma Bölümü, Tekirdağ \\ *Sorumlu yazar e-posta (Corresponding author; e-mail): surekhalil55@gmail.com
}

\section{Öz}

Bu çalışmanın amacı, çeltik tarlalarında sorun olan, kırmızı çeltik ve konvansiyonel çeltik yabancı ot ilaçlarına direnç gösteren yabancı otları kontrol etmek için, IMI (Imidozolinone) gurubu yabancı ot ilaçlarına dayanıklı çeltik çeşitleri geliştirmektedir. Bu araştırma, 2007 ve 2014 yılları arasında yürütülen 8 yıllık bir çalışmanın sonucunu içermektedir. Çalışmaya 2007 yılında, Trakya Tarımsal Araştırma Enstitüsünde, IMI gurubu yabancı ot ilaçlarına dayanıklı bir çeşit ile ticari çeltik çeşitleri arasında gerçekleştirilen 13 kombinasyon melez yapımı ile başlanmıştır. Bu melez kombinasyonları kullanılarak, bir ıslah çalışması gerçekleştirilmiştir. Melez kombinasyonlarından elde edilen popülasyonların seleksiyonunda, modifiye edilmiş bulk metodu kullanılmıştır. Bunun için $F_{2}$ 'de ekim ve hasat bulk şeklinde yapılmış ve $F_{3}$ 'de hasatta tek bitki seleksiyonuna başlanmıştır. Çalışmalar sonucunda; 2011 yılından itibaren durulmuş saf hatlar elde edilmeye başlanmıştır. Elde edilen hatlar, 2012 yılından itibaren, Trakya Tarımsal Araştırma Enstitüsü deneme tarlasında, tesadüf blokları deneme deseninde, üç tekerrürlü olarak verim denemelerine alınmaya başlanmıştır. Denemelerde agronomik ve teknolojik özellikler bakımından gözlem ve değerlendirmeler yapılmıştır. 2014 yılı sonunda, elde edilen sonuçların değerlendirilmesi sonucu, IMI yabancı ot ilaçlarına dayanıklı 5 ümit var hat, tescile aday gösterilmiştir. Bunlardan ikisine, 2014 yılının aralık ayında üretim izni alınmıştır. Bu hatlar, çeltik verimi, agronomik ve teknolojik özellikler bakımından Türk üreticisi ve tüketicisinin beğenisini kazanacak seviyededirler.

Anahtar Kelimeler: Çeltik (Oryza sativa L.), imidazolinone herbisit, IMI çeltik çeşidi, kırmızı çeltik

\section{Developing Some Herbicide Resistant Rice (Oryza sativa L.) Genotypes}

\begin{abstract}
The objective of this study was to develop IMI (Imidazolinone) group herbicide resistant rice varieties to control weedy rice (red rice) and the weed gained resistance against conventional rice herbicides in the rice fields. A resistant rice variety to IMI group herbicide was provided from abroad and it was utilised as resistance source in this study. This variety was crossed with Turkish commercial rice varieties at Trakya Agricultural Research Institute in 2007 and thirteen cross combinations were obtained. Some segregating material were created and the modified bulk selection method was practiced for the selection, for this the planting and harvesting were done as bulk at $F_{2}$ generation and the harvesting was practiced as single plant selection at $F_{3}$ generation. After selection the pure lines, they were tested in observation nursery, preliminary yield and yield trial, respectively. The yield trials were conducted in randomised complete block experiment design with three replications. Some selected IMI rice lines were tested in the yield trials in 2013 and 2014. Five of them had good performance in term of rice yield, agronomic and quality traits. They were nominated for registration as commercial varieties in the end of 2014. At the same time, the production permission was taken two of them, under the name of IMI 2521 and IMI 2554.
\end{abstract}

Keywords: Rice (Oryza sativa L.), imidazolinone group herbicide, IMI rice variety, red rice

\section{Giriş}

3 eltik dünyanın insan beslenmesi açısından en önemli ürünüdür ve dünya nüfusunun yarıdan fazlasının temel besin maddesidir. Dünya pirinç üretiminin yaklaşık \%90'nı Asya ülkelerinde üretilip tüketilmektedir. 2014 yılında dünyada toplam 163 milyon hektarlık bir alanda, 735 milyon ton çeltik üretilmiştir (Anonymous 2014). Ülkemizde, 2014 yılında 110 bin 
hektarlık sahada 830 bin ton çeltik üretilmiştir (Anonim 2014).

Kırmızı çeltik, kültürü yapılan çeltiğin yakın bir akrabasıdır. Bu nedenle, çeltikte yabancı ot kontrolünde kullanılan konvansiyonel çeltik yabancı ot ilaçları ile kontrol edilememektedir. Son zamanlarda; bazı mısır, ayçiçeği, kolza ve buğday ve çeltik gibi ürünlerde, geleneksel ıslah yöntemleri kullanılarak, imidazolinone gurubu yabancı ot ilaçlarına dayanıklılık sağlayan genotipler geliştirilmiştir. Bu yöntem, gerek kırmızı çeltiği gerekse konvansiyonel çeltik yabancı ot ilaçlarına direnç kazanan yabancı otları kontrol etmede, yeni bir çığır açmıştır.

Kırmızı çeltik, kültürü yapılan çeltik türlerinin otsu bir biotipidir. Kırmızı çeltiklerin çoğu kültür tipi olan $O$. sativa ve $O$. glaberrima'nın özelliklerini taşımaktadır (Khus 1997). Bollich et al., (2002) kırmızı çeltiğin karakteristik özelliklerini; kırmızı perikarplı tane, tane dökme, tohum dormansisi ile daha baskın gelişme özelliği olarak ifade etmişlerdir. Kırmızı çeltiğin kırmızı perikarp taşıması, bir dominant karakterdir ancak, birden fazla dominant genle idare edilmektedir (Leitao et al., 1972). Diğer taraftan, Li-hua et al. (2010) kırmızı perikarplılığın tek bir dominant gen tarafından kontrol edildiğini tespit etmişlerdir.

Kırmızı çeltiğin tane veriminde meydana getirdiği kayıp, ürün içerisinde bulunan kırmızı çeltik bitkisinin yoğunluk derecesine bağlıdır. $\mathrm{m}^{2}$ 'de 5, 108 ve 215 kırmızı çeltik bulunması, sırasıyla $\% 22, \% 77$ ve $\% 82$ ürün kaybına sebep olmuştur (Diarra et al. 1985). Güney Kore'de yapılan bir çalışmada ${ }^{2}$ 'de 62 kırmızı çeltik salkımı bulunması durumunda, \%22.1 ürün kaybı meydana gelmiştir. Diğer taraftan $\mathrm{m}^{2}$ 'de 100 adet kırmızı çeltik salkımı bulunduğunda, \%50'ye kadar varan verim kayıplarına rastlanmıştır (Pyon et al., 2000). Vongsaraj (2000) Tayland'da kırmızı çeltiğin \%60-80 arasında ürün kaybı meydana getirdiğini ve $\mathrm{m}^{2}$ 'de 150 kırmızı çeltik bitkisinin bulunmasının \%100'e varan ürün kaybı meydana getirdiğini bildirmiştir. Eleftherohorinos et al. (2002) Yunanistan'da yaptıkları bir çalışmada, kısa boylu Thaibonnet çeşidinin ekili olduğu tarlada $\mathrm{m}^{2}$ 'de $40 \mathrm{kırmızı}$ çeltik bitkisinin bulunmasının $\% 58$ tane verimi kaybı meydana getirdiğini belirlemişlerdir.

Baker and Sonnier (1983) kırmızı çeltik içeren mahsullerin, kırmızı perikarpının beyazlatılması için daha fazla beyazlatma işlemine tabi tutulması gerektiğini, bunun da kırıksız pirinç randımanını düşürdüğünü bildirmişlerdir. Kwon et al. (1991) m²'de 10 veya daha fazla kırmızı çeltik bitkisinin bulunmasının toplam ve kırıksız pirinç randımanı değerlerini düşürdüğünü tespit etmişlerdir. Chin et al. (2007) Vietnam'da farklı imidazolinone gurubu ilaçların, kırmızı çeltik ile birlikte, Echinochloa crus-galli, Leptochloa chinesis, Cyperus iria ve Cyperus diformis gibi otları da kontrol ettiğini gözlemişlerdir. Ottis et al. (2003) Texas ABD'de, IMI gurubu ilaçların, kırmızı çeltik bitkilerini \%94 ve Burgos et al. (2008) ise $\% 90$ oranında kontrol ettiğini tespit etmişlerdir. Meins et al. (2003) IMI gurubu ilaçlardan imazamox'un kırmızı çeltik kontrolü için, salkım çıkarma başlangıcı dönemine kadar kullanılabileceğini ortaya koymuşlardır.

Kırmız çeltik bitkilerini kontrol etmenin en ekonomik ve kesin şekli, bu bitkileri kontrol edebilen herbisitlere toleranslı çeşitler geliştirmektir. IMI çeltik, Louisiana Üniversitesi'nde Timomothy Croughan tarafından Ethyl Methyl Sulfonate (EMS) kullanılarak oluşturulan mutasyon materyalinden elde edilmiştir. Bu dayanıklı kaynaktan yararlanarak, ilk IMI çeltik çeşitleri ABD'de Louisiana Üniversitesi tarafından geliştirilerek, 1999 yılında CL 121 ve CL 141 isimleri altında tescil edilmiştir. Ticari olarak kullanılmaya 2002 yılında başlamıştır (Linscombe 2004; Tan et al. 2005).

ABD'de 2002 yılında sınırlı alanlarda ekilmeye başlayan, IMI gurubu ilaçlara toleranslı çeşitlerin ekim alanı, 2010 yılında güney eyaletlerde bulunan toplam çeltik ekim alanının \%60'nı işgal etmiştir (Linscombe 2010). Diğer taraftan, 2014 İtalya'da 220 bin hektar olan toplam çeltik ekim alanın \%35'inde IMI çeşitler ekilmiştir (Billoni 2014). Shivrain et al. (2006) imidazolinone gurubu herbisitlere toleranslıı̆ı̆ kısmi bir dominant gen tarafından idare edildiğini bildirmişlerdir, diğer taraftan Zhang et al. (2005) ve Lang et al. (2007) ise dayanıklılık mekanizmasının bir dominant gen tarafından kontrol edildiğini tespit etmişlerdir.

$\mathrm{Bu}$ çalışmanın amacı, çeltik tarlalarında sorun olan, kırmızı çeltik ve konvansiyonel çeltik yabancı ot ilaçlarına direnç gösteren yabancı otları kontrol etmek için, IMI (Imidozolinone) gurubu yabancı ot ilaçlarına dayanıklı çeltik çeşitleri geliştirmektir. Bunlar kırmızı çeltik ve söz konusu bu otların kontrolünde kullanılacaktır. 


\section{Materyal ve Yöntem}

Trakya Tarımsal Araştırma Enstitüsünde, yabancı ot ilaçlarına dayanıklılık çalışmaları, 2007 yılında başlatılmıştır. Bunun için, yurt dışından sağlanan ve IMI gurubu yabancı ot ilaçlarına dayanıkı bir çeşit, dayanıklılık kaynağı olarak kullanılmıştır. Bu çeşit, 2007 yılında ülkemizdeki bazı ticari çeşitler ile melezlenmişlerdir. Çizelge 1'de yapılan bu melez kombinasyonları görülmektedir.

\section{Açılan Materyal ve Verim Denemesi Çalışması}

$\mathrm{F}$ açılan materyalde, kısmi bulk metoduna göre seleksiyon işlemi uygulanmıştır. Bunun için $\mathrm{F}_{2}$ 'de ekim ve hasat bulk şeklinde yapılmış ve $\mathrm{F}_{3}$ 'de ise hasatta tek bitki seleksiyonuna başlanmıştır.

Elde edilen hatlar, önce gözlem bahçesi veya ön verim denemelerinde ve daha sonra verim denemelerinde denenmiştir. Gözlem bahçeleri kuru şartlarda sıraya ekilmiştir. Ön verim ve verim denemeleri için ekim, ön çimlendirme işlemi yapılmış tohumların su içerisine elle serpilmesi şeklinde yapılmıştır. Kuruya ekimlerde $\mathrm{m}^{2}$ ye 500 ve su içerisine yapılan ekimlerde ise 450 tane kullanıımıştır. Ön verim ve verim denemeleri tesadüf blokları deneme deseninde, üç tekerrürlü olarak kurulmuştur.

Araştırma materyalinin agronomik ve teknolojik özelliklerin gözlemi ve değerlendirilmesi, IRRI-1996'ya göre yapılmıştır. Denemelerin analizinde, MSTAT-C ve JMP istatistik programları kullanılmıştır.

Yabancı ot uygulaması için, dekara $8 \mathrm{~g}$ imazamox uygulaması yapılmıştır. 2013 yılında.konvansiyonel standart çeşitlere ilaç uygulaması yapılmadı, ancak, 2014 yılında uygulandı ve herbisit uygulamasından etkilenen bu çeşitler için 2014 yılında veri elde edilemedi. Bu durun, veri çizelgelerinde görülecektir.

\section{Bulgular ve Tartışma}

Seleksiyon çalışmaları sonucunda elde edilen hatlar, önce gözlem bahçesi ve verim denemelerinde denenmiştir. Daha sonra, söz konusu bu hatlar 2013 ve 2014 yıllarında verim denemelerinde değerlendirilmiştir. Çizelge 2'de ve çizelge 3'de görüldüğü gibi denemelerde yer alan hatlar arasında istatistiki olarak önemli farklııklar gözlenmiş̧ir.

2013 yılı verim denemesi sonucunda; çeltik verimi, agronomik ve kalite özellikleri bakımından öne çıkan 2007041-TR2521-1-2-1, 2007046-TR2526-2-1-1, 2007047-TR2527-2-12 ve 2007074-TR2554-2-2-1 çeşit adayı hatlar olarak seçilerek, 2014 yılında, IMI teknolojisinin tanıtımını yapmak amacıyla, bir lokasyonda çeşit demonstrasyonu çalışmasında kullanılmıştır. Çeşit demonstrasyonu ile ilgili sonuçlar çizelge 4'de verilmiştir. 2014 yılı verim denemsi sonucuna göre ise çeltik verimi, agronomik ve teknolojik özellikleri bakımından öne çıkan 2007041-TR2521-5-3-1, 2007044TR2524-4-1-1 ve 2007050-TR2530-4-1-1 hatları, 2014 yılı sonunda tescile aday gösterilmek üzere seçilmişlerdir. Ayrıca, demonstrasyon çalışmasında kullanılan hatlardan 2007041-TR2521-1-2-1 ve 2007074TR2554-2-2-1 hatları da tescile aday gösterilmiştir. Aynı zamanda, bu hatlara IMI 2521 ve IMI 2554 isimleri altında üretim izni alınmıştır. IMI çeşitler, ilk defa 2002 yılında ABD'de Louisiana Eyalet Üniversitesi tarafından ticari olarak kullanılmaya başlanmıştır.

IMI çeltik güvenli bir üründür, hiçbir transgenik bulaşma yoktur. IMI çeşitler, ilk defa 2002 yilında ABD'de Lousiana Eyalet Üniversitesi tarafından, ticari olarak piyasaya sürüldükten sonra, Amerika'da 2007-2011 yılları arasında CL 171-AR, CL 131, CL 151, CL 111, CL 261 ve CL 152 isimli IMI çeşitleri geliştirilmiş ve ticari olarak kullanılmaya başlanmıştır (Buehring 2008; Lincombe ve Sha 2011). Orta

Çizelge 1. 2007 yılında gerçekleştirilen melez kombinasyonu sayısı

Table 1. Hybrid combinations of 2007

\begin{tabular}{|c|c|c|c|c|c|}
\hline $\begin{array}{l}\text { Cross } \\
\text { No. }\end{array}$ & Pedigre & Melez kombinasyonları & $\begin{array}{l}\text { Cross } \\
\text { No. }\end{array}$ & Pedigre & Melez kombinasyonları \\
\hline 1 & 2007020-TR2500 & Osmancık-97 x IMI Çeşit & 8 & 2007048-TR2528 & IMI Çeşit x Krasnodarky-424 \\
\hline 2 & 2007041-TR2521 & IMI Çeşit x Durağan & 9 & 2007049-TR2529 & IMI Çeşit x KızıItan \\
\hline 3 & 2007043-TR2523 & IMI Çeşit x Halilbey & 10 & 2007050-TR2530 & IMI Çeşit x Edirne \\
\hline 4 & 2007044-TR2524 & IMI Çeşit x Ece & 11 & 2007051-TR2531 & IMI Çeşit x Şumnu \\
\hline 5 & 2007045-TR2525 & IMI Çeşit x Kıral & 12 & 2007074-TR2554 & Halilbey x IMI Çeşit \\
\hline 6 & 2007046-TR2526 & IMI Çeşit x Neğiş & 13 & 2007134-TR2614 & Gönen x IMI Ç̉şit \\
\hline 7 & 2007047-TR2527 & IMI Çeşit x Osmancık-92 & & & \\
\hline
\end{tabular}


ve Güney Amerika'da ABD'deki IMI (2004), Uruguay (2005), Arjantin (2005), çalışmalarını ilk takip eden ülkeler, yıllar Paraguay (2005), Bolivya (2005), Dominik itibarıyla, Nikaragua (2003), Panama (2003), Cumhuriyeti ve Honduras (2011)'dur (Gressel Kolombiya (2003), Brezilya (2003), Kosta Rica and Valverde, 2009; Kharkwal and Sha, 2009).

Çizelge 2. 2013 yılı IMI verim denemesi, çeltik verimi sonuçları $(\mathrm{kg} / \mathrm{da})$

Table 2. $2013 \mathrm{IMI}$ yield trial and rice yields ( $\mathrm{kg} / \mathrm{da})$

\begin{tabular}{|c|c|c|c|c|c|c|}
\hline \multicolumn{2}{|c|}{$\begin{array}{l}\text { Deneme Yeri } \\
\text { Deneme Deseni } \\
\text { Ekim Tarihi } \\
\text { Hasat Tarihi }\end{array}$} & \multicolumn{2}{|c|}{$\begin{array}{c}\text { EDİRNE (Merkez) } \\
\text { Tesadüf Blokları ( } 3 \text { tekerrür) } \\
\text { 15.05.2013 } \\
04.10 .2013\end{array}$} & \multicolumn{2}{|c|}{$\begin{array}{c}\text { Çeşit Sayısı } \\
\text { Ekim Alanı } \\
\text { Hasat Alanı } \\
\text { Gübre Dozu } \\
\end{array}$} & \multirow[t]{2}{*}{$\begin{array}{c}14 \\
20 \\
15.75 \mathrm{~m}^{2} \\
\mathrm{~N}_{15} \mathrm{P}_{8} \mathrm{~kg} / \mathrm{da} \\
\text { Verim sırası }\end{array}$} \\
\hline $\begin{array}{l}\text { Çeşit } \\
\text { No. }\end{array}$ & Çeşitler & $\begin{array}{l}2013 \text { Yılı } \\
\text { Gurupları }\end{array}$ & $\begin{array}{c}2013 \text { Yılı } \\
\text { Çeltik Verimleri }\end{array}$ & $\begin{array}{c}2012 \text { Yılı Çeltik } \\
\text { Verimleri }\end{array}$ & Orta. & \\
\hline 13 & 2007051-TR2531-1-3 & $a$ & 877.4 & $753.4 \mathrm{abc}$ & 815.4 & 2 \\
\hline 11 & 2007074-TR2554-2-2-1 & $a b$ & 846.3 & $801.1 \mathrm{a}$ & 823.7 & 1 \\
\hline 9 & 2007047-TR2527-2-1-2 & $a b c$ & 831.1 & $710.5 \mathrm{abcd}$ & 770.8 & 4 \\
\hline 8 & 2007046-TR2526-2-1-1 & abcd & 802.5 & 613.7 def & 708.1 & 12 \\
\hline 3 & 2007041-TR2521-1-2-1 & abcd & 801.2 & $733.3 \mathrm{abc}$ & 767.3 & 5 \\
\hline 7 & IMI Çeşit (St) & abcde & 794.9 & $726.1 \mathrm{abc}$ & 760.5 & 6 \\
\hline 2 & 2007020-TR2500-1-2-1 & abcde & 793.6 & $752.9 \mathrm{abc}$ & 773.3 & 3 \\
\hline 12 & 2007046-TR2526-2-2 & abcde & 791.1 & $664.4 \mathrm{cde}$ & 727.7 & 8 \\
\hline 4 & 2007043-TR2523-1-3-1 & abcdef & 784.7 & $675.3 \mathrm{bcd}$ & 730.0 & 7 \\
\hline 1 & Osmancık-97 (St) & bcdef & 770.1 & $664.2 \mathrm{cde}$ & 717.2 & 11 \\
\hline 5 & 2007043-TR2523-3-1-1 & cdef & 740.9 & 713.9 def & 727.4 & 9 \\
\hline 6 & 2007044-TR2524-1-2-2 & def & 737.8 & $704.0 \mathrm{abcd}$ & 720.9 & 10 \\
\hline 10 & 2007051-TR2531-3-1-1 & ef & 702.8 & $547.7 \mathrm{f}$ & 625.3 & 14 \\
\hline \multirow[t]{2}{*}{14} & Edirne $(\mathrm{St})$ & $\mathrm{f}$ & 692.7 & 571.1 ef & 631.9 & 13 \\
\hline & CV $(\%)=7$ & LSU $(\% 0)=$ & & $\mathrm{CV}(\%)=8$ & LSD ( & $5)=97.14$ \\
\hline
\end{tabular}

Çizelge 3. 2014 yılı IMI verim denemesi çeltik verimi sonuçları

Table 3. 2014 IMI yield trial and rice yields ( $\mathrm{kg} / \mathrm{da})$ )

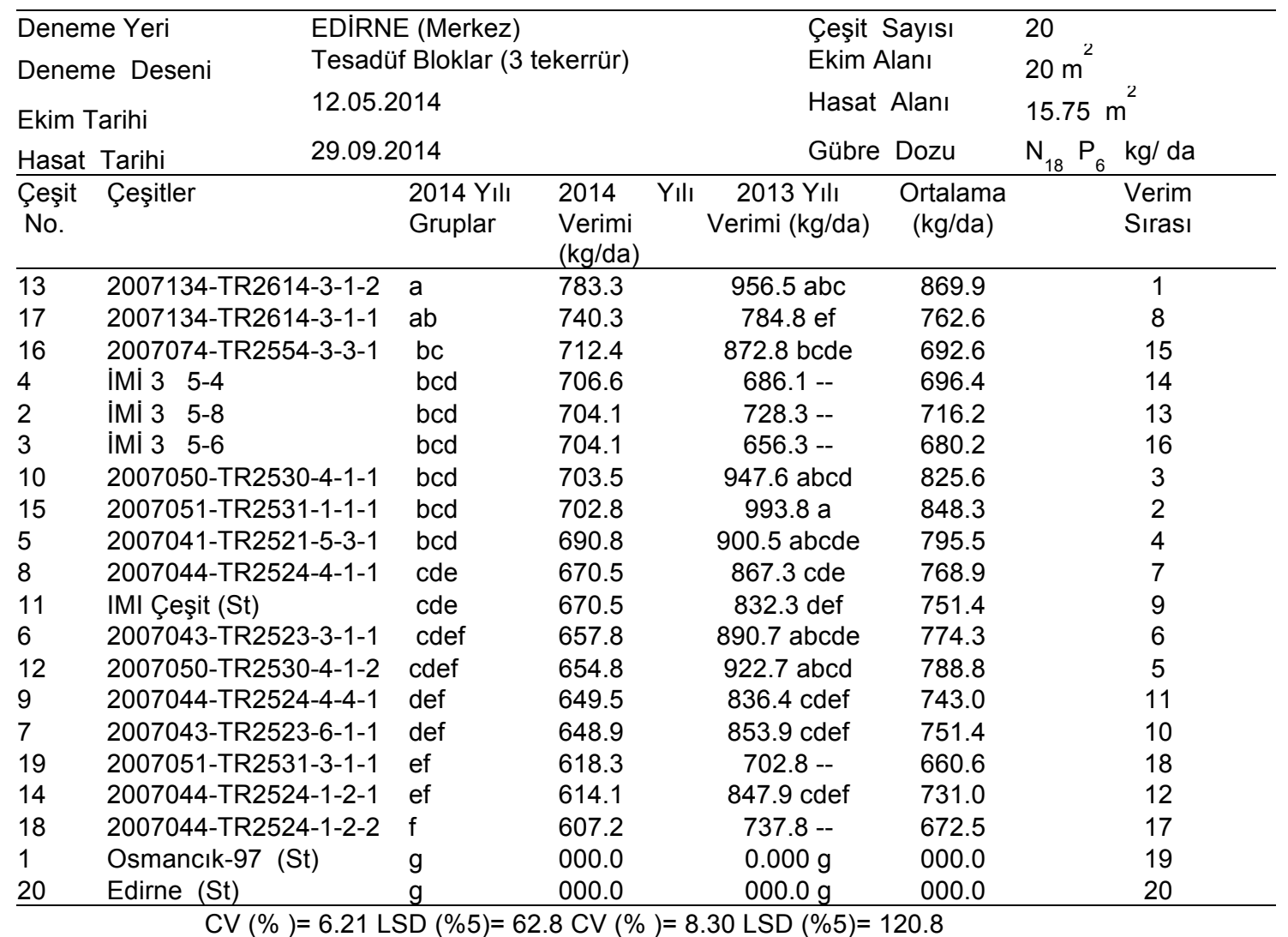


Çizelge 4. 2014 yılı IMI çeşit demonstrasyonu sonuçları

Table 4. 2014 IMI variety demonstration results

\begin{tabular}{|c|c|c|c|c|c|c|c|c|}
\hline \multicolumn{2}{|c|}{$\begin{array}{l}\text { İli: EDIRNE } \\
\text { İlçesi: Ipsala } \\
\text { Köyü: Paşaköy }\end{array}$} & \multicolumn{2}{|c|}{$\begin{array}{l}\text { Ekim Alanı: } 250 \mathrm{~m}^{2} \\
\text { Ekim Tarihi: } 27.05 .2014 \\
\text { Hasat Tarihi: } 09.10 .2014\end{array}$} & \multicolumn{5}{|c|}{$\begin{array}{l}\text { Tarla Sahibi: Sami Dubacı } \\
\text { Sorumlu Teknik Eleman: Okyay YATKIN } \\
\text { Çeşit Sayısı: } 5\end{array}$} \\
\hline $\begin{array}{l}\text { Çeşi } \\
\text { t No. }\end{array}$ & Çeşit Ad & & $\begin{array}{l}\text { Çeltik } \\
\text { Verimi } \\
\mathrm{kg} / \mathrm{da}\end{array}$ & $\begin{array}{l}\text { Toplam } \\
\text { Pirinç } \\
\text { Randım } \\
\%\end{array}$ & $\begin{array}{l}\text { Kırıksız } \\
\text { Pirinç } \\
\text { Randım } \\
\%\end{array}$ & $\begin{array}{l}\text { Çeltik } \\
1000 \\
\text { Dane } \\
\text { Ağır. g }\end{array}$ & $\begin{array}{l}\text { Pirinç } \\
1000 \\
\text { Dane } \\
\text { Ağır. g }\end{array}$ & $\begin{array}{l}\text { Pirinç } \\
\text { Tane } \\
\text { Görünüşü }\end{array}$ \\
\hline 1 & \multicolumn{2}{|c|}{ 2007041-TR2521-1-2-1 } & 542.0 & 71.7 & 66.5 & 26.7 & 20.0 & Camsı \\
\hline 2 & \multicolumn{2}{|c|}{ 2007046-TR2526-2-1-1 } & 422.0 & 64.0 & 54.0 & 30.6 & 26.8 & Bey. Göbekli \\
\hline 3 & \multicolumn{2}{|c|}{ IMI Çeşit (St) } & 606.4 & 70.0 & 66.0 & 22.4 & 17.7 & Camsı \\
\hline 4 & \multicolumn{2}{|c|}{ 2007047-TR2527-2-1-2 } & 593.3 & 72.4 & 65.0 & 28.0 & 21.2 & Camsı \\
\hline 5 & \multicolumn{2}{|c|}{ 2007074-TR2554-2-2-1 } & 576.8 & 68.8 & 64.5 & 26.2 & 21.6 & Camsı \\
\hline \multicolumn{3}{|c|}{ Demonstrasyon Ortalaması } & 548.1 & 69.38 & 63.2 & 26.8 & 21.5 & \\
\hline
\end{tabular}

Son zamanlarda, Asya ve Avrupa'da Malezya, Vietnam ve İtalya gibi ülkeler, IMI çeltik ıslahına ilgi duymuşlardır. Malezya'da MR220CL1 ve MR220CL2 IMI çeşitleri 2010 yılında tescil edilmiştir (Azmi et al. 2012; Biloni et al. 2014). Vietnam'da ABD'den sağlanan herbiside dayanıklı gen kaynağı kullanılarak yapılan IMI çeşit geliştirme çalışmaları devam etmektedir (Nguyan and Bui, 2007). Ülkemizde, Trakya Tarımsal Araştırma Enstitüsünde IMI çeltik çeşit geliştirme çalışmalarına, 2007 yılında başlanmıştır. 2014 yılı sonuna gelindiğinde, 5 IMI çeşit adayı hat tecile aday gösterilmiştir.

Bunlardan ikisine 2014 Aralık ayında üretim izni alınarak, 2015 yılında orijinal tohumluk üretimine başlanmıştır. IMI hatlarının, agronomik ve kalite özellikleri bakımından, konvansiyonel çeşitler ile mukayese edilebilir seviyede olduğu gözlenmiştir. Duong et al. (2007) Vietnam'da yaptıkları bir çalışmada, benzer durumu gözlemişlerdir. Diğer taraftan, Sha et al. (2007) Louisiana'da IMI çeşitlerin, konvansiyonel çeşitlerden daha düşük verim verdiğini, ancak, daha yüksek kırıksız pirinç randımanına sahip olduğunu tespit etmişlerdir.

\section{Sonuç}

ABD'de ilk IMI çeltik çeşitleri, 2002 yılında ticari olarak kullanılmaya başlanmıştır. Ülkemiz çiftçilerinin de bu teknolojiyi kullanmalarını sağlamak amacıyla, Trakya Tarımsal Araştırma Enstitüsünde, IMI gurubu yabancı ot ilaçlarına dayanıklı çeltik ıslahı çalışmalarına, 2007 yılında başlanmıştır. Bu çalışmalar sonucunda, 2014 yılı sonunda, 5 IMI aday hattının tescili için müracaatta bulunulmuştur. Ayrıca, bunlardan ikisine, IMI 2521 ve IMI 2554 isimleri altında üretim izni alınmıştır. Önümüzdeki yıllarda, çiftçilerimiz bu çeşitleri kullanarak, IMI teknolojisini kullanma imkanına sahip olacaklardır. Bu teknolojinin kullanılmasıyla, çiftçilere yabancı ot kontrolünde farklı bir seçenek sunulmuş olacaktır.

\section{Teşekkür}

Bu araştırma, 2013 ve 2014 yıllılarında TÜBITAK tarafından 1130106 Nolu proje çerçevesinde desteklenmiştir. TÜBITAK'a desteklerinden dolayı teşekkür ederiz.

\section{Kaynaklar}

Anonim, 2014. TC Başbakanlık TUiK 2014 Bitkisel Üretim İstatistikleri

Anonymous, 2014. Rice Market Monitor, 2014, XV1I ISSUE No. 4, p.30

Azmi M., Azlan S., Yim K.M., George T.V. and Chew S.E., 2012. Control of Weedy Rice in DirectSeeded Rice Using The Clearfield Production System In Malaysia. Pak. Weed Sci. Res., 18: 49-53

Baker J.B., Sonnier E.A., 1983. Red rice and its control. In: Proceedings of Weed Control in Rice (Ed. Inter. Rice Res. Inst.) 31 August-4 September 1981, Los Banos, Philippines. pp. 328-333

Biloni M., Diego G., Filip H., Tabacchi M., Andrea Z., Alvaro S. and Luis M., 2014. The Clearfield Rice Varieties in Europe. $4^{\text {th }}$ International Rice Conferance, 27 Oct.-01 Nov., 2014, Bangkok, Thailand. Abstract No: IRC14-0648

Bollich P.K., Salassi M.E., Webster E.P., Regan R.P., Romero G.R. and Walker D.M., 2002. An Evaluation of Clearfield Rice Production on a Stale Seedbed. Annual Southern Conservation Tillage Conf. for Sustainable Agriculture, 25 th, Spec. Rep. No:1 Auburn, Al. 24-26 June, Alabama Agric. Exp. Stn. And AAuburn Univ. AlL. Pp 184-189

Buehring N.W., 2008. Clearfield Rice, Mississippi State University Extension Service. http://msucares.com/publications/e0019.pdf (Accessed 24.12.11) 
Burgos N.R., Norsworthy J.K., Scott R.C. and Smith K., 2008. Red Rice (Oryza sativa) Status After 5 Years Of Imidazolinone-Resistant Rice Technology in Arkansas. Weed Technollogy, 22(1): 200-208.

Chin D.V., Thien T.C., Bi H.H. and Nhiem N.T., 2007. Study on weed and weedy rice control by imidazolinone herbicides in clearfield paddy grown by imi-tolerance indica rice variety. Omonrice, 15: 63-67

Diarra A.R.J., Smith R.J. and Taibert R.E., 1985. Growth and morphological characteristics of red rice (Oryza sativa) biotypes. Weed Sci., 33(5): 644-649

Duong V.C., Tran C.T., Huynh H.B. and Nguyen T.N., 2007. Study on weed and weedy rice control by imidazolinone herbicide in clearfield paady grown by imi-tolerant indica rice variety. Omonrice, 15: 63-67

Eleftherohorinos I.G., Dhima K.V. and Vasilakoglou I.B., 2002. Interference of red rice grown in grece. Weed Sci., 50(2): 167-172

Gressel J. and Valverde B.E., 2009. A strategy to provide long-term control of weedy rice while mitigating herbicide resistant transgenic flow, and its potential use for other crops with related weeds. Pest Manag. Sci., 65: 723-731

Gunawardana D., 2008. Harvesting Serendipity. Rice Today, 7(4): 36-39

Heiser J.W., Kending J.A., Smirt C.L. and Ezell P.M., 2005. Comparison of Imazethapyr and Imazamox as Either Primary or Salvage Herbicide in Imidazolinone-Resistant Rice. In: North Central Weed Science Proceedings, p.146

IRRI, 1996. Standart Evaluation System for Rice. $4^{\text {th }}$ Edition, July, 1996. Intrenational Rice Research Institute, Manila, Philippines

Kharkwal M.C. and Shu Q.Y., 2009. The Role of Induce Mutation in World Food Security. In Symposium on Induced Mutations in Plants. Food and Agric. Org. (FAO) of the United Nations, Rome, pp. 33-38

Khush G.S., 1997. Origin, dispersal cultivation and variation of rice. Plant Molecular Biology, 35: 25-34

Kwon S.L., Smith Jr. R.J. and Talbert R.E., 1991. Interference of red rice (Oryza sativa L.) densities in rice (Oryza sativa L.). Weed Sci., 39(4): 169-174

Lang N.T. and Buu B.C., 2007. Rice breeding and inheritance of herbicide resistance in clearfield rice (Oryza sativa L.). Omorice, 15: $36-45$
Leitao H.N., Banzato N. and Azzini L., 1972. Estudio de competicao entre o arroz vermelho e o arroz cultivado. Bragantia, 31: 249-258

Linscombe S., 2004. The Development an Introgression of Clearfield Technology into Commercial Rice Production. In: Proceeding of Conferance (Eds., Ferrero A, Vidotto F). Torino, Italy 13-15 September, 2004 pp. 348352

Linscombe S., 2010. Clearfield technology clears out red rice. Rice Today, 9(4): 44-45.

Linscombe S.D. and Sha X., 2011. Bred from louisiana, Rice Today, 10: 38-39

Meins K.B., Scott R.C., Dillon T.W. and Pearrow N.D., 2003. Tolerance of Clearfield Rice to Imazamox. AAES Research Series 517, pp:132-136

Nguyen T.L., Bui C.B., 2007. Rice breeding and inheritance of herbicide resistance in clearfield rice (Oryza sativa L.). Omonrice, 15: 36-45

Ottis B.V., Chandler J.M. and Mccauley G.N., 2003. Imazethapry application methods and sequence for imidazolinone-tolerant rice (Oryza sativa). Weed Technology, 17(3): 526533

Pyon J.Y., Kwon W.Y. and Guh J.O., 2000. Distribution, Emergence, and Control of Korean Weedy Rice. In: Proceedings of Wild and Weedy Rice in Rice Ecosystems in Asia (Eds., Baki BB, Chin DV, Mortimer M) IRRI, Los Banos, Philippines, pp.37-40

Shivrain V.K., Burgos N.R., Moldenhauar K.A., McNew K., Ronald W. and Baldwin T.L., 2006. characterization of spontaneous crosses between clearfield rice (Oryza sativa) and red rice (Oryza sativa). Weed Technology, 20(3): 576-584

Tan S., Evans R.R., Dahmer M.L., Singh B. and Shanar D.L., 2005. imidazolinone-tolerant crops: history, current status and future. Pest management Sci., 61(3): 246-257

Thurber C.S., Reagon M., Olsen K.M., Jia Y. and Caicedo A.L., 2014. The Evolution of Flowering Strategies in US Weedy Rice. American Journal of Botany, 101: 1737-1747

Vongsaroj P., 2000. Wild and Weedy Rice in Thailand. In: Proceedings of Wild and Weedy Rice in Rice Ecosystems in Asia (Eds., Baki BB, Chin DV, Mortimer M) IRRI, Los Banos, Philippines. pp. $55-57$

Zhang W., Linscombe S.D., Webster E., Tan S. and Oard J., 2006. Risk assessment of the transfer of imazethapyr herbicide tolerance from clearfield rice to red rice (Oryza sativa). Euphytica, 152(1): 75-86 